\title{
Operations Research: An indispensable toolkit for the logistician
}

\author{
WJ Pienaar* \\ Received: 10 November 2004; Revised: 23 February 2005; Accepted: 1 March 2005
}

\begin{abstract}
This paper traces the origin of the word logistics, outlines its conceptual evolution, and explains its meaning in contemporary usage. The background that led to the introduction of Logistics Management and Operations Research (OR) as undergraduate fields of study at the University of Stellenbosch is sketched. The concept of Logistics Management is described and its strategic, tactical and operational tiers, as well as the different activities that form part of the logistics supply chain process are identified. The role and necessity of OR in decision-making within each activity and in the coordination between the various activities are outlined. OR techniques most pertinent to the field of logistics are identified and the analytical competencies that a logistician should possess are indicated.
\end{abstract}

Key words: Coordination, Customer Service, Efficiency, Effectiveness, Logistics, Operations Research, Project Management, Supply Chain Management, Trade-off Analysis.

\section{Introduction}

Economic life in South Africa during the 1980s and 1990s was marked by rapid change. First, the economic deregulation of freight transport and the marketing of agricultural produce, the globalisation of business activities and liberalisation of international trade, and the lifting of trade sanctions against the country made transport decision-making more market-driven. Second, the development of effective information technology, easy electronic communication, the ability to perform comprehensive and complicated numeric analyses through the use of information technology, and new holistic management approaches have made it possible to manage logistics channels and other complicated processes in a coordinated fashion, almost in real time. These trends convinced the University of Stellenbosch in 1991 to introduce Logistics Management as a field of study. Subsequently several tertiary teaching institutions in South Africa have done the same.

Successful business logistics practice requires that decisions reached must be quantitatively sound, mainly because of the various cost trade-offs and coordination involved in the

${ }^{*}$ Department of Logistics, University of Stellenbosch, Private Bag X1, Matieland, 7602, South Africa, email: wpienaar@sun.ac.za 
logistics decision-making process. The focus of coordinated and integrated management is lowest total process cost, not achievement of the lowest cost of each function in the process [3]. This statement reminds one of the adage that "sub-optimisation is the name of the devil." To support and enhance the Logistics Management courses, the Department of Logistics of the University of Stellenbosch makes extensive use of Operations Research in its teaching and research programmes. Operations Research can indeed be regarded as an indispensable analytical toolkit for the logistician. The principles of Operations Research are logically consistent. Therefore, an integrated logistics process with cross-functional coordination achieved through the application of Operations Research methodology should lead to better results than one lacking coordinated performance [1].

\section{Evolution of the concept of logistics}

The word logistics is derived from the Greek adjective logistikos, which means skilled in calculating, relating to arithmetic or which is concerned with reason. The adjective is derived from the verb logizomai, meaning to calculate, to reason or to think. The verb is based on the word logos, which is translated as reason, word or discourse, depending on the context.

The Greek logistikos entered the main European languages via the Low Latin logisticus, which became logistique in French. The French feminine noun logistique first began appearing in 1546. In Discourse on Poliphile's Dream, published in 1593, reason is represented by a character called Logistique (He who reasons) [2]. In 1611 the noun logistique is used with reference to the four basic processes of arithmetic and algebra (adding, subtracting, multiplying and dividing). In 1765 the adjective logistique, meaning with reference to calculation, was derived from this noun [7].

The introduction of the word logistique — recognized by the French Academy in 1840 [8] - to describe the art of combining and coordinating the quartering, means of transport, supplying and supporting of troops through reasoning by calculation during a military campaign is attributed to Antoine Henri, Baron of Jomini. Jomini served as a brigadiergeneral in Napoleon's army. He first used the word in 1836 in this context in his seminal work Précis de l'art de la guerre (Summary of the art of war) [15, 16].

In line with the meaning that Jomini attached to the word logistics Plowman (1964) has commented as follows: "Logistics, a plural word derived from logistic, means, in military science, the planning and handling and implementation of personnel, also the related material, facilities, and other factors. Thus logistics means the application of reasoning, especially mathematical analysis and synthesis, to the complex and inter-related problems of coordinating manpower and supplies and barracks. Military logistics is a major factor in making it possible for an army to march and fight and win its battles. Defined thus, military logistics includes the interrelated and largely mathematical procedures, and the resulting coordinating decisions." 


\section{Emergence of logistics in a business context}

After the devastation caused in Western Europe during the Second World War, Jomini's legacy of military logistics gave birth to what later became known as business logistics. That war crippled much of Western Europe's infrastructure and capital stock. Huge areas of farmland that became battlefields during the war were also not readily available for agricultural activities.

Once the hostilities had been terminated in 1945, the economic reconstruction of Western Europe began. Experts specialising in different fields of logistics and operations research, no longer needed for warfare, were employed in this reconstruction and revitalisation. The countries involved in this regional effort were Belgium, France, West Germany, Italy, Luxembourg, and the Netherlands.

The efforts to revive this region were intense and concerted. It was deemed imperative that primary production, secondary manufacturing and tertiary service delivery had to come into their own soon in order for Western Europe to regain economic self-sufficiency. The restoration, and even improvement above previous standards, of local and intra-regional accessibility and mobility was afforded precedence, as it was clear that Western Europe's recovery would best be served through cooperation, regional specialisation, intra-regional sourcing, and the creation of a common market. The catalyst through which this was to be achieved was the operationalisation of an effective logistics system derived from the military model. Within the region logistics chains emerged as if no international borders existed.

The above-mentioned six countries established the European Community (EC) as a regional organisation in 1958 through the Treaty of Rome. The treaty provided for the gradual elimination of intra-regional customs duties and other trade barriers, the establishment of a common external tariff against other countries, the gradual integration of a common agricultural policy and guarantees of free movement of labour, capital and physical resources [12]. By this time coordinated logistics practice had taken root in Western Europe. The strategy of constructing and coordinating logistic channels that linked points of primary production within regions of specialization with points of ultimate consumption and use was well understood.

The French Academy recognized the use of the word logistics in a business context (in addition to the military meaning) in 1960 and attached the following meaning to the word: "Ensemble de moyens et de méthodes concernant l'organisation d'un service, d'une entreprise et spécialement les flux de matières avant, pendant et après une production" (All means and methods of organising a service, a business and especially the flow of materials before, during and after production) [8].

The first textbook outside Europe to suggest the benefits of coordinated logistics management appeared in 1961, in part explaining why a generally accepted definition of business logistics was still in the process of emerging [20]. Although focused primarily on physical distribution management, i.e. management of the flow of products from manufacturing to the place of consumption or use, the book also refers to the flow of goods between the origin of resources and the place of product manufacture - recognizably based on the French interpretation of business logistics. 
Ruppenthal (1963), Director of the First Annual Business Logistics Forum held in 1962 at Stanford University, published the first comprehensive overview of business logistics, which placed the concept in context. He stated:

"No competent military commander would dream of mounting an offensive until he was reasonably assured of logistic support. The responsible general must know that supplies will be produced in adequate number, and that they will be available when and where they were needed. This important feature of availability has long been known as logistics - the physical movement of materials and supplies from the source of supply to the place of ultimate consumption.

In business, too, the logistics function is an essential link - in this case, between production and marketing. Business logistics is concerned with the inbound movement of materials and supplies, and the outward movement of finished products. Its goal is the delivery of the finished products called for by the marketing department to the point where they are needed, when they are needed, and in the most economical fashion.

No modern business establishment can afford to be dismembered into neat compartments; instead, all departments are interrelated. It is this interdependence among the departments of modern business that is the subject of business logistics. To ignore business logistics, to ignore the indivisible nature of the business enterprise of today, is to invite extinction."

\section{The concept of business logistics management}

The Council of Supply Chain Management Professionals (CSCMP), the major supply chain management and logistics professional organisation in the USA, defines Logistics Management as "that part of Supply Chain Management that plans, implements, and controls the efficient, effective forward and reverse flow and storage of goods, services and related information between the point of origin and the point of consumption in order to meet customers' requirements" [5]. According to the CSCMP "Supply Chain Management encompasses the planning and management of all activities involved in sourcing and procurement, conversion, and all Logistics Management activities. Importantly, it also includes coordination and collaboration with channel partners, which can be suppliers, intermediaries, third-party service providers, and customers. In essence, Supply Chain Management integrates supply and demand management within and across companies" [5]. The CSCMP views Logistics Management as an integrating function, which coordinates and optimises all logistics activities, as well as integrates logistics activities with other functions, including marketing, manufacturing, finance and information technology [5]. The CSCMP's definition of logistics is the generally accepted description of the concept in contemporary business logistics management literature. Some comments on this definition are in order:

First, as the definition indicates, business logistics management includes the actions required to (a) prepare (plan), (b) organise (implement) and (c) execute (control) the activities of a firm when moving materials or finished products to customers [4]. Preparation and planning activities include the selection of (i) facility sites (including type, number, location, and size and capacity), (ii) durable equipment necessary for the flow of products 
through the logistics network, (iii) distribution parties (including wholesalers, retailers and thirdparty service providers) and (iv) carriers (including choice of transport mode) necessary to offer service at the level demanded by customers to achieve the goals of the firm. The organisational and implementation aspects of logistics include (i) the allocation and positioning of resources and (ii) the fixing of production and distribution activities to respond to customer needs in an efficient manner in order to accomplish the firm's goals. Execution includes operational aspects (such as routing of trips and scheduling of vehicles and crews) and control includes monitoring and reviewing performance (such as quality of service, expenditures, productivity and asset utilisation) so as to ensure that (i) the logistics process satisfies customers effectively, (ii) the firm's resources are deployed efficiently and (iii) corrective action is taken when performance is not in line with goals.

Second, because logistics management revolves around planning, organising, and executing/controlling the logistics process, it encompasses many of the firm's activities, from the strategic level through the tactical to the operational level. Logistical decisions are typically classified in the following way [10]:

- The strategic level (i.e. preparation and planning) deals with decisions that have a longlasting effect on the firm. Because data are often incomplete and imprecise, strategic decisions are generally based on aggregated data (obtained, for example, by grouping individual products into product families and aggregating individual customers into customer zones).

- The tactical level (i.e. organisation and implementation) includes decisions that are updated any time between once every month and once a year. Tactical decisions are often based on disaggregated data.

- The operational level (i.e. execution and control) refers to day-to-day decisions. Operational decisions are customarily based on very detailed data.

Third, an objective in logistics management is to be efficient and effective across the entire system. This objective can be achieved by minimising systemwide costs, from transportation, materials handling and distribution (on the one hand) to warehousing and keeping inventory of raw material, semi-finished goods and finished products (on the other hand). Thus, the emphasis is not on simply the cheapest or the fastest transport or reducing inventories, but rather on an integrated and coordinated systems approach to the logistics process. The integrated total-cost concept is the trade-off of all costs that are in conflict with each other and that can affect the outcome of a particular logistics decision [3]. The acceptance of the total-cost logistics concept has changed the relative importance of the different logistics activities and has led to cost trade-offs between transport/materials handling services provided and the operation of warehouse and production facilities assuming greater importance. For example, traditional wisdom is that materials can be handled most efficiently by using maximum size mechanical means to reduce the number of moves needed for a given amount of material. While reducing the number of trips required is a good objective, the drawback of this approach is that it tends to encourage the acceptance of large production lots, large material handling equipment, and large space requirements. Small unit loads allow for more responsive and less expensive material handling systems. 
Furthermore, continuous manufacturing flow processes necessitate the use of smaller unit loads.

Cost minimisation ought to be confined only to eliminating waste and not pruning costs at the expense of greater revenue. Reducing logistics costs makes sense only if the foregone profits are smaller than the cost reduction. Similarly, the acceptance of additional logistics costs - for example, an airfreight delivery instead of delivery with a cheaper but slower mode of transport, but which is not offset by lower inventory carrying cost or other logistics cost savings - is justified only if net revenue increases as a result. The optimal level of logistics expenditure occurs where marginal expenditure (i.e. the expenditure attributed to the last unit of output) equals marginal revenue (i.e. the revenue attributable to the last unit of output). To reflect this, the CSCMP definition of logistics management can be adjusted to read as follows for business logistics management:

"Business logistics management is the process of planning, organising, executing and controlling the efficient, effective flow and storage of goods, services and related information between the place of origin and the place of consumption or application for the purpose of optimally meeting customer requirements in order to help maximise the welfare of the firm." [22]

If a firm can consistently provide its customers with the desired quality and quantity of products, where and when needed, at acceptable cost, it can gain market share advantage over its competitors. The firm might be able to sell its products at a lower cost as a result of logistics efficiencies, or provide a higher level of customer service as a result of logistics effectiveness, or both, thereby gaining a competitive edge in the market.

Customer service acts as the binding and unifying force for all of the logistics activities. Customer satisfaction occurs when the firm's manufacturing, marketing and logistics effort is successful, thus adding sufficient value (or creating enough utility) to prevent the customer from procuring the product in an alternative way. Each activity of a firm's logistics system can affect whether a customer receives the right product and information at the right place and time in the right condition and quantity at the right cost/price. Optimal customer service involves well-managed logistics in order to provide the necessary level of customer satisfaction (i.e. effectiveness) at the lowest possible total cost (i.e. efficiency) in order to contribute maximally towards the firm's welfare.

\section{Business Logistics activities}

The following activities are involved in the flow of product and information between place of origin and place of consumption or application: Demand forecasting, Facility site selection, Procurement, Materials handling, Packaging, Warehousing, Inventory management, Order processing, Logistics communications, Transport, Waste disposal, Return goods handling, and Parts and service support [22]. Each of these activities is described separately in this section. 


\subsection{Demand forecasting}

Demand forecasting involves determining the amount of product and accompanying information that customers will require in the future, whether in the short or long run. The need to know how much product will be demanded is important for (a) marketing, (b) manufacturing, and (c) logistics. Marketing forecasts of future demand determine promotional strategies, allocation of sales force effort, pricing strategies, market research activities, and manufacturing scheduling and sizing. Manufacturing schedules determine acquisition strategies, plant inventory decisions and right-sizing production capacity in line with marketing forecasts. Logistics management forecasts of demand determine how much of each item produced by the firm must be transported to the various markets it serves. Also, logistics management must determine where the demand will occur so that appropriate volumes of goods can be made available in each market area. Knowledge of future demand levels enables logistics managers to allocate their resources (budgets) to activities that will service that demand.

\subsection{Facility site selection}

The type, layout, location, number and size/capacity of facilities are of strategic importance. For example, the placement of sales facilities near the firm's markets can improve customer service. Proper facility location can also allow lower total transport costs from the location of raw materials or primary producers through the logistics chain to the customer. The first consideration in selecting a site is the location of the firm's various resources and markets. The needs of customers and the location of raw materials and other inputs are major considerations, because the firm must be concerned with inbound movement and storage of materials in addition to outbound flows. Other important factors include (a) labour costs, (b) transport costs, (c) land and construction costs, (d) property rates and taxes, (e) availability of utilities, services and infrastructure, (f) security, (g) legal concerns, and (h) local factors, such as the attitude of the community towards new industries.

\subsection{Procurement}

Procurement is the acquisition of goods, services and information to ensure the operating effectiveness of the firm's manufacturing and marketing processes. The procurement function includes (a) the selection of resources and suppliers, (b) determination of the form in which the inputs are to be acquired, (c) timing and coordination of incoming goods arrival, (d) price negotiation, and (e) quality control of incoming goods.

\subsection{Materials handling}

Materials handling is concerned with every aspect of the (off-road) movement or flow of raw materials, semi-finished goods and finished goods on a premises and within a facility. Successful materials handling contributes toward reducing inventory, lowering costs and increasing productivity. 


\subsection{Packaging}

Packaging performs two basic functions - marketing and logistics. In a marketing sense the package acts as a form of promotion and advertising. Its size, mass, colour, appearance and printed information can attract attention and convey knowledge about the product. From a logistics perspective, packaging serves a dual role. First, the package protects the product from damage and perhaps prevents a product from damaging other goods through any potential hazards it might possess. Second, packaging can make it easier to store and move products by reducing handling, thereby lowering materials handling and distribution costs.

\subsection{Warehousing}

Warehousing entails the activities that manage the space needed to hold or maintain inventories. Goods must be stored for later sale and consumption unless customers need them immediately after production. Generally, the greater the time lag between production and consumption, the larger the quantity of inventory required. Specific warehouse management decisions include (a) warehouse location, capacity and design, (b) whether the storage facility should be owned or rented, (c) level of mechanisation or automisation, (d) goods mix considerations, (e) security and maintenance, (f) personnel training, and (g) productivity measurement.

\subsection{Inventory management}

Inventory management is a critical issue. The needs of both manufacturing and marketing have to be met continuously. However, large volumes of inventory occupy capital-intensive warehouse space, while possession of the inventory itself requires financial sacrifice. The cost of warehouse space and the value of the inventory both have an opportunity cost. An optimal trade-off must be reached between this opportunity cost and the harmful effects that will emanate from a stockout situation. This clearly illustrates the importance of accurate demand forecasting in order to satisfy customer needs without sacrificing efficiency.

\subsection{Order processing}

Order processing relates to those activities associated with filling customer orders. These include (a) transmittal of the order details to the sales section, (b) verifying the customer's creditworthiness, (c) transmittal of the consignment's required packaging details to inventory control staff for delivery to the despatch section, (d) preparation of the shipment documentation, and (e) communicating the order status, the method of payment and the delivery details to the customer.

The time duration and accuracy of a firm's order processing are important determinants of the level of customer service it provides. Advanced automatic systems, such as electronic data interchange and electronic funds transfer can reduce the time between order placement and shipment from a warehouse. Such systems, although initially expensive, can substantially improve both order-processing accuracy and order-response time. Often 
savings in other logistics expenses (such as inventory control, transport, and warehousing) or increased sales from improved customer service will justify the investment cost of the system.

\subsection{Logistics communications}

Successful logistics usually requires the effective management of information and communications systems. Effective communication must take place between (a) the firm and its customers, (b) the firm and its suppliers, (c) the major functional components of the firm - for example, marketing, manufacturing and logistics, (d) the various logistics activities, such as procurement, warehousing, order processing, inventory control and transport, and (e) the various components of each logistics activity. Accurate and timely communication is the cornerstone of successfully integrated and coordinated logistics management.

\subsection{Transport}

The movement of goods is a key activity and usually the largest cost component of the logistics process. It includes decisions on aspects such as: (a) operating one's own transport versus hiring transport, (b) mode, carrier and service selection, (c) freight consolidation, (d) vehicle routing and crew and trip scheduling, and (e) vehicle selection, replacement timing and acquisition (i.e. purchase, lease, or rent).

\subsection{Waste disposal}

Waste is a side-effect of the manufacturing process. If waste can be re-used or recycled, logistics manages its handling, storage and carriage to plants. If it cannot be recycled, it must be disposed of. In the case of hazardous material special disposal standards and environmental regulations need to be heeded. Waste disposal will assume greater importance as recycling and environmental considerations gain greater significance.

\subsection{Return goods handling}

The handling of return goods is an integral part of the logistics process. Customers may return goods to the seller due to defects, excesses, or wrong items received. Often logistics systems are incapable of handling goods movement on return or contra-flow trips. Whenever customers return items for warranty repair, replacement or recycling, costs may be high, especially when returned goods cannot be transported, stored and/or handled easily. Return goods handling promises to become even more important as customers demand more flexible and lenient goods return policies, especially where there is effective product competition.

\subsection{Parts and service support}

Part of the firm's marketing activity is often to provide customers with after-sale service. This involves providing replacement parts when products malfunction. Logistics is responsible for ensuring that parts are available where and when the customer needs them. 
Product failure can be costly to the customer if it results in an interruption in production. In order to ensure customer satisfaction, the firm supplying the replacement part must be able to respond promptly.

\section{Operations Research competencies required in logistics practice}

The Department of Logistics at the University of Stellenbosch educates both logistics managers and logisticians. The former may be regarded as primarily "model users" while the latter can claim to be "model builders." Prospective logistics managers need to pursue Logistics Management and another economics or management-related subject as compulsory major subjects - typically Marketing Management. To become a graduate logistician at the University of Stellenbosch requires that Logistics Management and Operations Research be followed as major subjects. Both prospective logistics managers and logisticians have to take Project Management as additional (third) subject in the final year. In contrast to Business Logistics, which the Department views as a recurring flow process within product supply chains, it views Project Management as the logistic arrangements of one-off events - referred to by some as "event logistics." Project Management entails the careful preparation, organisation, execution and control of a complicated activity or operation so that it happens in an efficient and effective way.

Operations Research is taught on undergraduate level in the second and third year within the three-year BSc and BComm degree programmes. Students who wish to take Operations Research on undergraduate level are required to pass, on the first year level, a semester module in Probability Theory and Statistics as well as the two semester modules Calculus and Linear Algebra, which in combination comprise Mathematics I. Those who wish to follow Operations Research and Logistics Management as major subjects also need to pass the first year one semester module in Theory of Interest.

The research that preceded the design of an undergraduate Operations Research curriculum in 2000, and a revision thereof during 2004, entailed three steps: First, the experience gained by the Department of Logistics through teaching the subject Logistics Management since 1992 was used to help judge which quantitative ("model using") skills are required by logistics managers and which quantitative ("model building") skills are needed by logisticians. Second, the opinion of currently practicing logistics graduates, employers of qualified logisticians, and organised commerce and industry was sought to determine which quantitative competencies a logistician should ideally possess. Third, a study of the content of twelve authoritative internationally used Logistics and Operations Research textbooks was undertaken to determine which Operations Research methods and techniques are discussed most in a logistics context. These publications were in turn divided into three groups. The first group comprised the five best selling Logistics Management textbooks. These books focus primarily on the management of product supply chains. The authors of these texts treat the appropriate Operations Research techniques mainly from a modelusing point of view. The following five textbooks were consulted: Bowersox et al. (2002), Ballou (2004), Coyle et al. (1996), Johnson et al. (1998), and Lambert et al. (1998). The second group comprised Operations Research textbooks that address logistics and supply 
chain analysis from a model-building viewpoint. The following three publications were consulted: Bramel and Simchi-Levi (1997), Ghiani et al. (2004), and Simchi-Levi et al. (2004). The third group comprised four mainstream Operations Research textbooks. Due cognizance was taken of which applications dealt with in the latter group of publications are best suited for and appropriate in logistics practice. The following four publications were consulted: Gass and Harris (1996), Hillier and Lieberman (2001), Taha (1989), and Winston (2004). During the curriculum design in 2000 the immediate previous editions of references $[1,3,11,23]$ were used.

During the 2000 survey "practicing logistics graduates, employers of qualified logisticians, and organised commerce and industry" were categorised as being part of the primary (production) sector, the secondary (manufacturing) sector or the tertiary (service) sector. From the primary sector responses and views were obtained from agricultural cooperatives and farming enterprises (6), mining companies (3), fishing companies (2) and forestry representatives (3). From the secondary sector responses and views were obtained from industrialists who manufacture intermediary products (i.e. semi-finished goods) (8), finished durable products (4) and final consumer goods (6). In the tertiary sector opinions were solicited from wholesalers (4), retailers and grocery chains (5), financial institutions (3) and transport and distribution service providers in both the private and public sectors (22). Not all of the respondents could nuance exactly the range of Operations Research competencies and specific applications they required from a logistician. However, all of them could at least broadly indicate the nature of the Operations Research proficiencies that they required from logisticians.

The required competencies identified by the 14 respondents in the primary sector could be grouped into six of the competencies listed in Table 1. From most sought to lesser sought, these competencies rank as follows: Make rational decisions, forecasting, facility location, scheduling, control inventory levels and determine routes for vehicles. The competency needs of the 18 respondents in the secondary sector ranked as follows: Scheduling, control inventory levels, determine routes for vehicles, make rational decisions, location of facilities, forecasting, analysis with simulation and apply queuing theory. The required competencies identified by the 34 respondents in the tertiary sector ranked as follows in order of decreasing importance: Forecasting, make rational decisions, scheduling, determine routes for vehicles, control inventory levels, location of facilities, analysis with simulation and apply queuing theory. On an aggregated basis the survey conducted by the Department showed that graduate logisticians should first and foremost possess the following five Operations Research competencies: (i) Make rational decisions, (i) forecasting, (iii) scheduling, (iv) determine routes for vehicles and (v) control inventory levels. The five most important Operations Research techniques to achieve these competencies are: (i) Linear programming, (ii) integer programming, (iii) feasibility analysis, (iv) transportation modelling, and (v) deterministic and probabilistic inventory modelling.

During the 2004 review of the content of the undergraduate Operations Research curriculum the opinion of six former students who became practicing logisticians were obtained. Discussions with them indicated that the eight identified fields of competency were sufficient, but that feasibility analysis as a methodology (with its subordinate cluster of techniques) had to be added, and that more emphasis on statistical methodology was 


\begin{tabular}{|c|c|}
\hline Competencies & OR-techniques \\
\hline Forecasting & $\begin{array}{l}\text { Exponential smoothing }{ }^{5} \\
\text { Linear regression analysis and the least-squares } \text { method }^{5} \\
\text { Markov analysis }\end{array}$ \\
\hline Analysis with simulation & $\begin{array}{l}\text { Discrete-event simulation }{ }^{6} \\
\text { Random numbers and Monte Carlo simulation }{ }^{6} \\
\text { Simulations with continuous random variables }\end{array}$ \\
\hline Make rational decisions & $\begin{array}{l}\text { Utility theory }^{5} \\
\text { Feasibility analysis } \\
\text { Decision trees }^{5} \\
\text { Marginal analysis } \\
\text { Multi-criterion decision analysis }\left(\mathrm{AHP}^{5} \text {, Goal Programming }^{5}\right) \\
\text { Linear programming }\end{array}$ \\
\hline Location of facilities & $\begin{array}{l}\text { Network models (centre, median, requirement problems, } \\
\text { covering problems) } \\
\text { Location in perpendicular coordinates } \\
\text { Linear programming }^{4}\end{array}$ \\
\hline Determine routes for vehicles & $\begin{array}{l}\text { Heuristic models (Clarke-Wright, Travelling salesperson, } \\
\text { Chinese postperson) }^{4} \\
\text { Transportation modelling }^{4} \\
\text { Assignment } \\
\text { Transhipment }^{4} \\
\text { Integer programming }^{5,6}\end{array}$ \\
\hline Control inventory levels & $\begin{array}{l}\text { Deterministic models }(\mathrm{EOQ})^{4} \\
\text { Probabilistic models }{ }^{5} \\
\text { Linear programming }^{4,5} \\
\text { Integer programming } \\
\text { Dynamic programming } \\
\text { Nonlinear programming }\end{array}$ \\
\hline $\begin{array}{l}\text { Schedule machines, projects, } \\
\text { vehicles and crews }\end{array}$ & $\begin{array}{l}\text { Machines: Algorithms (Lawler's and Johnson's Algorithms) } \\
\text { Projects: CPM and PERT } \\
\text { Vehicles: Heuristics, integer programming }{ }^{4,5,6} \\
\text { Crew: Heuristics, integer programming } \\
4,5\end{array}$ \\
\hline Apply queuing theory & $\begin{array}{l}\text { Birth-death processes }{ }^{6} \\
\text { Poisson arrivals }{ }^{6} \\
\text { Exponential and Erlang service times } \\
\text { Queue networks } \\
\text { Chi square test }^{6}\end{array}$ \\
\hline
\end{tabular}

Table 1: Identified areas of Operations Research competency and analysis techniques needed to be mastered in an undergraduate Logistics programme. (The superscripts refer to the semester in which the techniques are taught. Semester 3 refers to the first semester of the second year, through semester 6 that refers to the second semester of the third year.) 
necessary. During the 2004 curriculum revision the Department also had the opportunity to consider the recommendations made by the team of external evaluators who officially evaluated the Department's academic offering in 2002. In the field of Operations Research their recommendation that Heuristic Algorithms should be introduced as a technique at undergraduate level, was implemented.

Apart from the prerequisite first year modules in Mathematics and Probability Theory, Statistics and Theory of Interest referred to above, and the utilisation of financial, mathematical and statistical analysis techniques included in the subjects of Logistics Management and Project Management, the above-mentioned investigation indicated that logisticians-in-training should become competetent in at least eight of the functional areas of Operations Research. These areas of competency are: (i) forecasting, (ii) analysis with simulation, (iii) decision-making, (iv) facility location, (v) route planning, (vi) inventory control, (vii) scheduling and (viii) application of queuing theory.

Table 1 lists the specific Operations Research techniques that are taught during each semester at undergraduate level by the Department of Logistics at the University of Stellenbosch to achieve each identified logistics competency. Operations Research, as offered in the Department of Logistics at undergraduate and postgraduate level, entails more techniques and competencies than those shown in Table 1, because the subject is not taught exclusively to educate logisticians.

\section{Conclusions}

Since the Second World War the meaning of logistic(s) has been extended to fields other than the traditional military environment and has also been used in a business context since the early 1960s. In this context logistics may be described as the process of preparing, organising, executing and controlling the efficient, effective flow and storage of goods, services and related information between the place of origin and the place of consumption or application for the purpose of optimally meeting customer requirements in order to help maximise the welfare of the firm. In this context logistics is regarded as a flow process within product supply chains. In addition to the military and business interpretations of the term logistics, it can also be seen as the management of one-off events and operations, i.e. projects. Project Management entails the careful preparation, organisation, execution and control of a complicated activity or operation so that it happens in an efficient and effective way.

Regardless of whether the word is used in a military, recurring business flow or one-off project context, the objective of logistics is to ensure that the desired products (i.e. goods and services) and information are made available at the designated place and time in the required condition and quantity at an acceptable cost or price. An integrated logistics process with cross-functional coordination achieved through the application of Operations Research methodology should lead to the mentioned acceptable cost or price.

Before commencing with the subject of Operations Research at undergraduate level at the University of Stellenbosch students should have passed the prerequisite modules in Calculus, Linear Algebra, Statistics and Probability Theory, and Theory of Interest. 
The ability to apply Operations Research methodology effectively is an imperative for successful logistics practice. Operations Research may be regarded as an indispensable toolkit for the logistician. The following eight tools are the most important instruments in this kit: (i) forecasting, (ii) analysis with simulation, (iii) decision-making, (iv) facility location, (v) route planning, (vi) inventory control, (vii) scheduling and (viii) application of queuing theory. Of these eight tools graduate logisticians should first and foremost possess the following five Operations Research competencies: (i) Make rational decisions, (ii) forecasting, (iii) scheduling, (iv) determine routes for vehicles and (v) control inventory levels. The five most important Operations Research techniques to achieve these competencies are: (i) Linear programming, (ii) integer programming, (iii) feasibility analysis, (iv) transportation modelling, and ( $\mathrm{v}$ ) deterministic and probabilistic inventory modelling.

\section{References}

[1] BALlou RH, 2004, Business logistics/supply chain management, $5^{\text {th }}$ Edition, Prentice-Hall, Englewood Cliffs (NJ).

[2] Boucher C, 1998, Logistique, Private facsimile communication received from Professor Claude Boucher, University of Sherbrooke, Canada, on the etymology of the word logistique in the French language, (Facsimile copy available from the author) Montréal.

[3] Bowersox DJ, Closs DJ \& Cooper MB, 2002, Supply chain logistics management, McGraw-Hill, New York (NY).

[4] Bramel J \& Simchi-Levi D, 1997, The logic of logistics: Theory, algorithms, and applications for logistics management, Springer-Verlag, New York (NY).

[5] Council of supply Chain management professionals, 2005, Supply chain management/logistics management definitions, [Online], [Cited 21 February 2005], Available from http://www.cscmp.org/Website/AboutCSCMP/ Definitions/Definitions .asp.

[6] Coyle JJ, Bardi EJ \& Langley CJ, 1996, The management of business logistics, $6^{\text {th }}$ Edition, West, New York (NY).

[7] Dictionnaires Le Robert, 1976, Petit Robert: Dictionnaire Alphabétique et Analogique de la Langue Francais, Paris.

[8] Dictionnaires Le Robert, 1996, Petit Robert: Dictionnaire Alphabétique et Analogique de la Langue Francais, Paris.

[9] Gass SI \& Harris CM, 1996, Encyclopedia of operations research and management science, Kluwer, Boston (MA).

[10] Ghiani G, Laporte G \& Musmanno R, 2004, Introduction to logistics systems planning and control, Wiley, Chichester. 
[11] Hillier FS \& Lieberman GJ, 2001, Introduction to operations research, $7^{\text {th }}$ Edition, McGraw-Hill, New York (NY).

[12] Hinkelman EG, 2000, Dictionary of international trade: Handbook of the global trade community, $4^{\text {th }}$ Edition, World Trade Press, Novato (CA).

[13] Johnson JC, Wood DF, Wardlow DI \& Murphy PR (JR), 1998, Contemporary logistics, $7^{\text {th }}$ Edition, Prentice-Hall, Upper Saddle River (NJ).

[14] Lambert DM, Stock JR \& Ellram LM, 1998, Fundamentals of logistics management, McGraw-Hill, Homewood (IL).

[15] Macksey K \& Woodhouse W, 1991, The Penguin encyclopedia of modern warfare: 1850 to the present day, Viking, London.

[16] Parkinson R, 1977, Encyclopedia of modern war, Routledge, London.

[17] Plowman EG, 1964, Lectures on elements of business logistics, Graduate School of Business, Stanford University, Stanford (CA).

[18] Ruppenthal KM, 1963, New dimensions in business logistics, Proceedings of the First Annual Business Logistics Forum 1962, Graduate School of Business, Stanford University, Stanford (CA).

[19] Simchi-Levi D, Wu SD \& Shen Z, 2004, Handbook of quantitative supply chain analysis: Modelling in the e-business era, Kluwer, Boston (MA).

[20] Smykay EW, Bowersox DJ \& Mossman FH, 1961, Physical distribution management, Macmillan, New York (NY).

[21] TAнA HA, 1989, Operations research: An introduction, $4^{\text {th }}$ Edition, Macmillan, New York (NY).

[22] Vogt JJ, PienaAR WJ \& De Wit PWC, 2002, Business logistics management: Theory and practice, Oxford University Press, Cape Town.

[23] Winston WL, 2004, Operations research: Applications and algorithms, $4^{\text {th }}$ Edition, Thomson, Belmont (CA). 
